\title{
Allergen-specific Th1 cells fail to counterbalance Th2 cell-induced airway hyperreactivity but cause severe airway inflammation
}

\author{
Gesine Hansen, ${ }^{1}$ Gerald Berry, ${ }^{2}$ Rosemarie H. DeKruyff, ${ }^{1}$ and Dale T. Umetsu ${ }^{1}$ \\ ${ }^{1}$ Division of Immunology and Transplantation Biology, Department of Pediatrics, and \\ ${ }^{2}$ Department of Pathology, Stanford University, Stanford, California 94305-5208, USA \\ Address correspondence to: Rosemarie H. DeKruyff, Department of Pediatrics, Room S323, Stanford University, Stanford, California \\ 94305-5208, USA. E-mail: RDK@stanford.edu
}

Received for publication September 8, 1998, and accepted in revised form November 18, 1998.

\begin{abstract}
Allergic asthma, which is present in as many as $10 \%$ of individuals in industrialized nations, is characterized by chronic airway inflammation and hyperreactivity induced by allergen-specific Th2 cells secreting interleukin-4 (IL-4) and IL-5. Because Th1 cells antagonize Th2 cell functions, it has been proposed that immune deviation toward Th1 can protect against asthma and allergies. Using an adoptive transfer system, we assessed the roles of Th1, Th2, and Th0 cells in a mouse model of asthma and examined the capacity of Th1 cells to counterbalance the proasthmatic effects of Th2 cells. Th1, Th2, and Th0 lines were generated from ovalbumin (OVA)-specific T-cell receptor (TCR) transgenic mice and transferred into lymphocyte-deficient, OVA-treated severe combined immunodeficiency (SCID) mice. OVA-specific Th2 and Th 0 cells induced significant airway hyperreactivity and inflammation. Surprisingly, Th1 cells did not attenuate Th2 cell-induced airway hyperreactivity and inflammation in either SCID mice or in OVA-immunized immunocompetent $\mathrm{BALB} / \mathrm{c}$ mice, but rather caused severe airway inflammation. These results indicate that antigen-specific Th1 cells may not protect or prevent Th2-mediated allergic disease, but rather may cause acute lung pathology. These findings have significant implications with regard to current therapeutic goals in asthma and allergy and suggest that conversion of Th2-dominated allergic inflammatory responses into Th1-dominated responses may lead to further problems.
\end{abstract}

J. Clin. Invest. 103:175-183 (1999).

\section{Introduction}

Chronic inflammation of the respiratory mucosa plays a fundamental role in the pathogenesis of asthma, which affects as many as $10 \%$ of individuals in industrialized nations (1). The inflammatory response in asthma is tightly associated with airway hyperresponsiveness, a hallmark of asthma, and involves a number of different cell types including eosinophils, basophils, mast cells, and, most importantly, CD4 ${ }^{+}$Th2 lymphocytes, which can be isolated from the lungs of patients with asthma $(2,3)$. Th2 cells secreting interleukin-4 (IL)-4 and IL-5 play a central role in initiating and sustaining an asthmatic response by regulating the production of IgE and the growth, differentiation, and recruitment of mast cells, basophils, and eosinophils (4). Persistent wheezing in children is predicted by development of IgE-mediated hypersensitivity to inhaled allergens (5), indicating that the development of an inappropriate adaptive Th2-polarized immune response to environmental antigens plays a critical role in the development of asthma.

While Th2 cells promote airway inflammation in asth$\mathrm{ma}$, it has been proposed that Th1 cells, which secrete interferon (IFN)- $\gamma$, protect against allergic disease by dampening the activity of Th2 effector cells. The evidence, however, demonstrating that Th1 cells actually render salutary effects in allergic disease and asthma, is indirect. Th1 cells inhibit the proliferation, and therefore the development, of Th2 cells (6), and IFN- $\gamma$ inhibits IgE synthesis in some instances (7). Allergen-specific Th1 clones can be generated from nonallergic individuals (8), but the frequency of such cells in asymptomatic individuals is not clear, particularly given that such cells are not found in the nasal or pulmonary mucosa of nonallergic individuals. Conventional immunotherapy for allergic diseases and asthma reduces IL-4 production in allergenspecific Th2 cells (9) and increases IFN- $\gamma$ production by allergen-specific Th1 cells $(10,11)$. Individuals predisposed toward the production of Th1 cytokines (e.g., patients with multiple sclerosis) have a reduced likelihood of developing allergic disease (12). Finally, infection with Mycobacteria tuberculosis, which requires a Th1dominated immune response for eradication, reduces the likelihood of developing atopy (13).

These studies together suggest that immunotherapies for asthma should promote the replacement of allergenspecific Th 2 cells with Th1 cells, which counterbalance the effects of Th2 cells. No data are available, however, that directly show that Th1 cells actively suppress Th2dominated allergic responses. Recent studies with Th1 and Th 2 cells in autoimmune encephalomyelitis and diabetes mellitus indicate that Th2 cells may not always antagonize Th1 cells and that polarized Th2 cells that are generally assumed to be protective in autoimmunity may in some instances be unexpectedly harmful (14-16). These studies indicate that the Th1/Th2 paradigm may be much more complex than initially appreciated.

The purpose of this study was to examine directly the capacity of Th1 $\mathrm{CD} 4^{+}$cells to counterbalance the allergic 

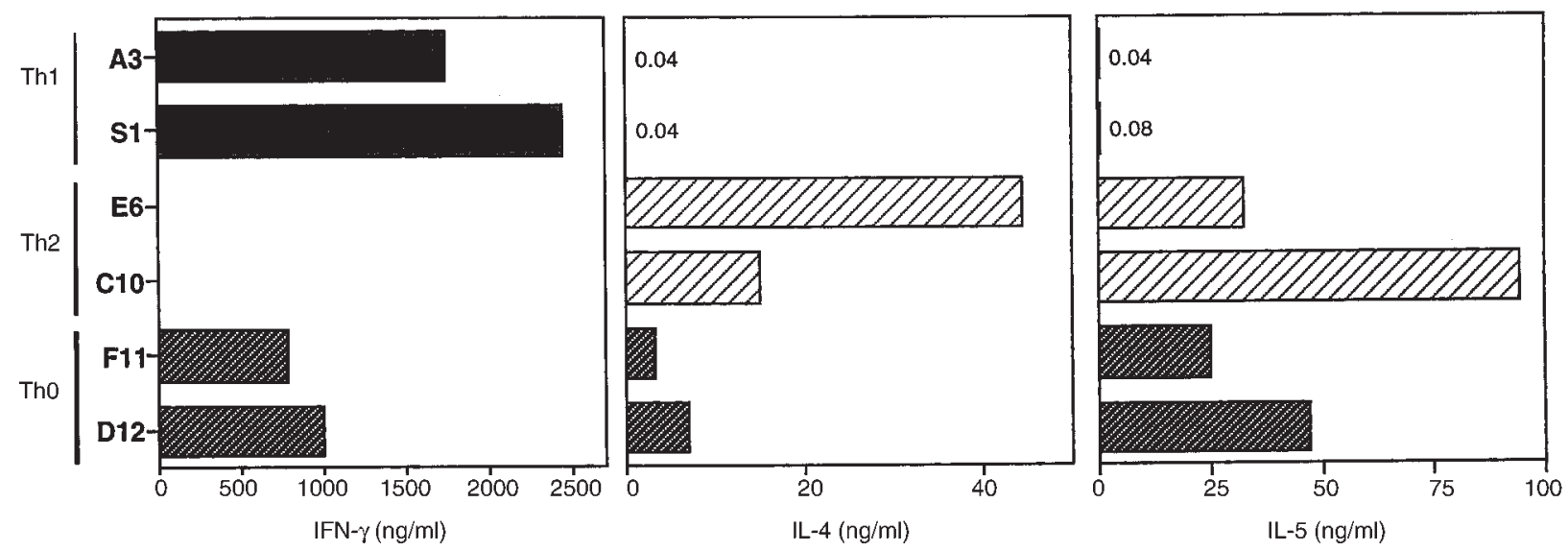

Figure 1

Cytokine profiles of OVA-specific Th cell lines used in these studies. Th1, Th2, and Th0 cell lines $\left(10^{6} \mathrm{cell} / \mathrm{s} / \mathrm{ml}\right)$ were stimulated with ConA ( $\left.1 \mu \mathrm{g} / \mathrm{ml}\right)$ for $18 \mathrm{~h}$. Supernatants were collected and analyzed by ELISA for IFN- $\gamma$, IL-4, and IL-5. IFN, interferon; IL, interleukin; OVA, ovalbumin.

effects of Th2 cells in a murine model of asthma. Th1, $\mathrm{Th} 2$, and $\mathrm{Th} 0 \mathrm{CD}^{+}$lines expressing identical ovalbumin (OVA)-specific T-cell receptors (TCRs) were generated from OVA-specific TCR transgenic mice, and their effects after transfer into lymphocyte-deficient severe combined immunodeficiency (SCID) and immunocompetent $\mathrm{BALB} / \mathrm{c}$ mice on allergen-induced airway inflammation and airway hyperreactivity were investigated. Our results demonstrated that OVA-specific Th1 cells caused severe airway inflammation and did not reduce the inflammatory effects of OVA-specific Th2 cells. OVA-specific Th1 cells did not induce airway hyperreactivity but were unable to reduce Th2 cell-induced airway hyperreactivity, either in lymphocyte-deficient SCID mice or in immunocompetent recipients. These results indicate that antigen-specific $\mathrm{CD}^{+}$Th1 cells may not be protective in Th2-mediated allergic diseases and asthma, but instead cause significant pulmonary disease. These findings are of particular concern with regard to current therapeutic goals in asthma and allergies, and suggest that conversion of Th2-dominated allergic inflammatory responses into Th1-dominated responses may be problematic.

\section{Methods}

Animals. BALB/cBy mice were obtained from The Jackson Laboratory (Bar Harbor, Maine, USA), and histocompatible C.B17Icrscid/scid mice (17) were obtained from the Stanford Medical Center Division of Laboratory Animal Medicine (Stanford, California, USA). DO11.10 mice, which are transgenic for TCR recognizing OVA peptide 323-339 (pOVA $^{323-339}$ ) and backcrossed to BALB/c (18), were kindly provided by $\mathrm{D}$. Loh and were bred in our facilities. Animals were used between 6 and 10 weeks of age and were age and sex matched within each experiment. All animal protocols were approved by the Stanford University Committee on Animal Welfare.

Monoclonal antibodies and reagents. Anti-IFN- $\gamma$ monoclonal antibody (MAB) R46A2 (HB170, ATCC) and anti-IL-4 MAB (11B11) (both generously provided by J. Ohara and B. Paul, National Institutes of Health, Bethesda, Maryland, USA) were prepared from serum-free culture supernatants by ammonium sulfate precipitation. Anti-IL-2 MAB S4B6, anti-IFN- $\gamma$ antibody XMG1.2, and anti-IL-5 MABs TRFK-4 and TRFK-5 were obtained from T. Mosmann (University of Alberta, Edmonton, Alberta, Canada). Anti-IL-4 MABs BVD4-1D11 and BVD6-
24G2 were obtained from M. Howard (DNAX Research Institute, Palo Alto, California, USA). Each of these antibodies was purified from ascites by ammonium sulfate precipitation and ion-exchange chromatography. Neutralizing anti-IL-12 MAB C17.8, a generous gift of G. Trinchieri (The Wistar Institute, Philadelphia, Pennsylvania, USA), was purified from ascites by affinity chromatography. Hybridoma cells producing anticlonotype antibody KJ1-26.1 were generously provided by P. Marrack (National Jewish Medical Center, Denver Colorado, USA)(19). M. Howard (Anergen Inc., Redwood City, California, USA) generously provided murine rIL-4, and the Genetics Institute (Boston, Massachusetts, USA) generously provided rIL-12.

Preparation of OVA-specific Th1 and Th2 cells. OVA-specific Th1, Th2, and Th0 lines were generated from spleen and lymph node cells from DO11.10 (OVA TCR Tg) mice. T cells bearing the DO11.10 TCR were purified from spleen by negative selection on anti-Ig-coated plates, followed by positive selection using the anticlonotype antibody KJ1-26.1 and MACS anti-mouse IgG2a plus IgG2b microbeads. T cells were cultured at $5 \times 10^{5}$ per well with $4 \times 10^{6}$ irradiated spleen cells as Antigen-presenting celts (APC) and OVA (ICN Biomedicals, Costa Mesa, California, USA) $(50 \mu \mathrm{g} / \mathrm{ml})$. To generate Th2 lines, rIL-4 $(40 \mathrm{U} / \mathrm{ml})$ and anti-IL-12 MAB $(10 \mu \mathrm{g} / \mathrm{ml})$ were added to the cultures. Th0 lines were generated with the addition of rIL-4 $(20 \mathrm{U} / \mathrm{ml})$ and rIFN- $\gamma(5 \mathrm{ng} / \mathrm{ml})$, but not anti-IL-12, to the cultures. Th1 lines were generated by culturing $\mathrm{T}$ cells purified from lymph nodes of the DO11.10 mice in the presence of anti-IL-4 MAB and rIL-12 $(0.1 \mathrm{ng} / \mathrm{ml})$. After 7 days, cells were washed, counted, and restimulated with APC and antigen under the same conditions used for the initial stimulation. After the $T$ cell lines achieved a stable committed phenotype (by the third cycle of stimulation), the $\mathrm{T}$ cell lines were maintained by weekly stimulation with APC and OVA without addition of anti-cytokine antibodies. Th1 lines were maintained with periodic addition of rIL-2. The cytokine profiles of the Th1, Th0, and Th2 lines were confirmed, by direct examination of supernatants generated from these lines, using ELISA for IL-4, IL-5, and IFN- $\gamma$, assays all well- established in our laboratory.

Transfer of cells. Th cell lines were transferred into histocompatible SCID mice. To facilitate homing of the $\mathrm{T}$ cell lines to the lungs, SCID mice were given $50 \mu \mathrm{g}$ OVA in $50 \mu \mathrm{l} \mathrm{NaCl} 0.9 \%$ intranasally 1 day before intravenous transfer of cells. To facilitate pulmonary aspiration, mice were lightly anesthetized intraperitoneally with $0.25 \mathrm{ml}$ of ketamine $(0.44 \mathrm{mg} / \mathrm{ml}) / x y l a z i n e ~(6.3 \mathrm{mg} / \mathrm{ml})$ in normal saline. Seventy-five percent of the intranasally administered antigen can be subsequently detected in the lungs (20). 
Cultured Th1 or Th2 cells were harvested and washed with PBS. The results of pilot experiments suggested that transfer of $2.5 \times 10^{6}$ Th cells into syngeneic SCID recipients produced results similar to those observed when $5 \times 10^{6}$ or $7.5 \times 10^{6} \mathrm{Th}$ cells were transferred. Therefore, $2.5 \times 10^{6}$ cells were adoptively transferred intravenously in most experiments. Some mice received a mixture of Th 1 and Th 2 cells $\left(2.5 \times 10^{6}\right.$ cells each or 5 $\times 10^{6} \mathrm{Th} 1$ plus $2.5 \times 10^{6} \mathrm{Th} 2$ cells). Control mice received either OVA intranasally but $\mathrm{NaCl} 0.9 \%$ instead of $\mathrm{T}$ cells intravenously, or they received T cells intravenously but $\mathrm{NaCl} 0.9 \%$ instead of OVA intranasally. One and 2 days after the adoptive transfer of cells, OVA was again administered intranasally. Airway hyperreactivity was determined $24 \mathrm{~h}$ after the last intranasal dose of antigen was administered. Bronchoalveolar lavage (BAL) and lung fixation were performed the following day.

Immunization protocol of normal $B A L B / c$ mice to induce airway byperreactivity. Th1 cell lines were also transferred into OVAimmunized $\mathrm{BALB} / \mathrm{c}$ mice. $\mathrm{BALB} / \mathrm{c}$ mice were immunized with OVA intraperitoneally $(50 \mu \mathrm{g})$ complexed with aluminum potassium sulfate (alum) on days 1 and 14 , and intranasally (50 $\mu \mathrm{g}$ OVA in $50 \mu \mathrm{l}$ of PBS) on days $14,25,26$, and 27 . Control mice received intraperitoneal injections of alum alone and intranasal PBS. Some mice received Th1 cells intravenously $(2.5$ $\times 10^{6}$ cells per mouse) on days 14 and 25 . Airway hyperreactivity to inhaled methacholine was measured $24 \mathrm{~h}$ after the last intranasal dose of OVA (day 28). BAL and lung fixation were performed the following day (day 29).

Measurement of airway responsiveness. Airway responsiveness was assessed by methacholine-induced airflow obstruction from conscious mice placed in a whole-body plethysmograph (model PLY 3211; Buxco Electronics Inc., Troy, New York, USA). Pulmonary airflow obstruction was measured by Penh (see eq. 1 ).

$$
\text { Penh }=\left(\frac{T e}{R T}-1\right) \times\left(\frac{P E F}{P I F}\right)
$$

Penh $=$ enhanced pause (dimensionless), $\mathrm{Te}=$ expiratory time, $\mathrm{RT}=$ relaxation time, $\mathrm{PEF}=$ peak expiratory flow $(\mathrm{ml} / \mathrm{s})$, and PIF = peak inspiratory flow $(\mathrm{ml} / \mathrm{s})(21)$. Enhanced pause (Penh), minute volume, tidal volume, and breathing frequency were obtained from chamber pressure, measured with a transducer (model TRD5100; Buxco Electronics) connected to preamplifier modules (model MAX2270; Buxco Electronics), and analyzed by system XA software (model SFT 1810; Buxco Electronics). Measurements of methacholine responsiveness were obtained by exposing mice for $2 \mathrm{~min}$ to $\mathrm{NaCl} 0.9 \%$ (Portable Ultrasonic 5500D; DeVilbiss Health Care Inc., Sommerset, Pennsylvania, USA), followed by incremental doses $(2.5-40 \mathrm{mg} / \mathrm{ml})$ of aerosolized methacholine and monitoring Penh. Results were expressed for each methacholine concentration as the percentage of baseline Penh values after $\mathrm{NaCl} 0.9 \%$ exposure.

Collection of BAL fluid. Animals were injected intraperitoneally with a lethal dose of phenobarbital $(450 \mathrm{mg} / \mathrm{kg})$. After tying off the left lung at the mainstem bronchus, the trachea was cannulated; the right lung was then lavaged with $0.4 \mathrm{ml}$ of PBS three times and the fluid pooled. Cells in the lavage fluid were counted using a hemocytometer, and BAL cell differentials were determined on slide preparations stained with Hansel Stain (Lide Laboratories, Florissant, Montana, USA). At least 200 cells were differentiated by light microscopy based on conventional morphologic criteria.

Lung histology. After washing with PBS, one part of the left lung was fixed in $10 \%$ formalin and stained with hematoxylin and eosin. The other part of the lung was embedded in OCT compound (Tissue Tec; Miles Inc., Elkhart, Indiana, USA), snap-frozen in liquid nitrogen, and stored at $-80^{\circ} \mathrm{C}$ until sectioning. Then, $6-\mu \mathrm{m}$ sections were fixed in acetone and stained with the biotinylated anticlonotypic antibody KJ1-26.1 and Streptavidin-FITC (PharMingen, San Diego, California, USA). A biotinylated anti-human IL-10 antibody (JES-312G8-biotinylated) was used as control antibody.

Cytokine ELISA. ELISAs were performed as described previously (22). The antibody pairs used were as follows, listed by capture/biotinylated detection: IFN- $\gamma$, R4-6A2/XMG1.2; IL-4, 11B11/BVD6-24G2; IL-5, TRFK-5/TRFK-4. The standards were recombinant cytokine curves generated in 1:2 dilutions from 20 to $0.156 \mathrm{ng} / \mathrm{ml}$ for IFN- $\gamma, 500$ to $7.5 \mathrm{pg} / \mathrm{ml}$ for IL-4, and 5,000 to $40 \mathrm{pg} / \mathrm{ml}$ for IL-5.

\section{Results}

Generation and characterization of OVA-specific Th1, Th0, and Th2 cells. Th1, Th0, and Th2 cell lines were generated from OVA-specific $T$ cells purified from the lymph nodes or spleen of OVA-specific TCR DO11.10 transgenic mice. $\mathrm{CD}^{+} \mathrm{T}$ cells were stimulated by OVA in the presence of rIL-4 and anti-IL-12 MAB to generate Th2 cell lines, whereas Th0 lines were generated by addition of rIL-4 and IFN- $\gamma$, but not anti-IL-12 MAB, to the culture. Th1 lines were generated by culturing OVA-specific T cells in the presence of anti-IL-4 MAB and rIL-12. They were maintained by weekly stimulation with irradiated APC and OVA, and Th1 lines required periodic addition of rIL-2. Figure 1 shows the cytokine content of supernatants from each Th cell line, as analyzed by ELISA for IL-4, IL-5, and IFN- $\gamma$. The Th1 cell lines produced high levels of IFN- $\gamma$ but no detectable IL-4. In contrast, the Th2 cell lines produced high levels of IL-4 but no detectable IFN- $\gamma$. The Th0 cell lines produced both IFN-
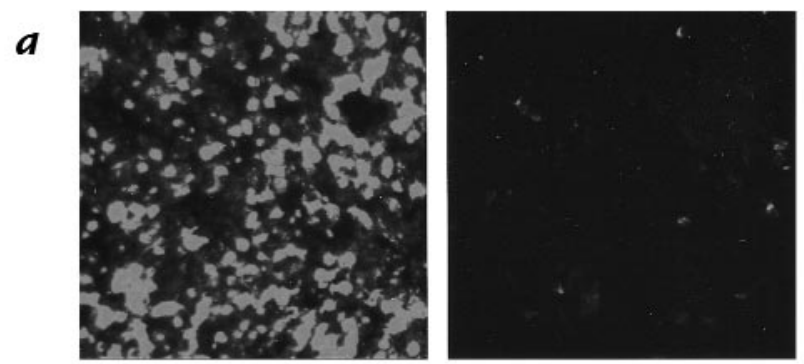

$\boldsymbol{b}$
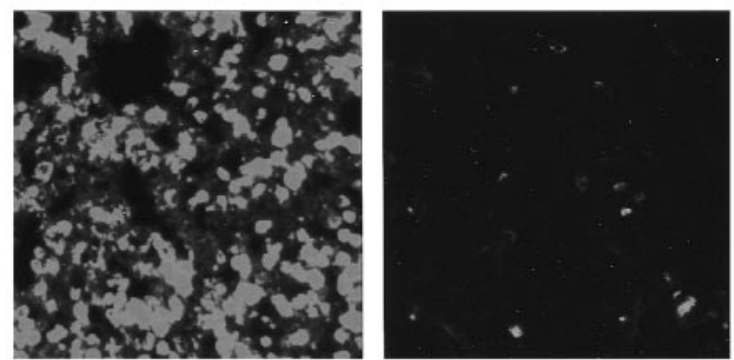

Figure 2

OVA-TCR transgenic Th cells migrate to the lungs of recipient mice. Four days after adoptive transfer of OVA-specific Th cell lines $\left(2.5 \times 10^{6}\right.$ cells per mouse), mice were sacrificed and lung tissue was embedded in OCT compound. Frozen sections were obtained and stained with biotinylated anticlonotype antibody, KJ1-26.1 or biotinylated control antibody JES-312G8 and Streptavidin-FITC. (a) Lung tissue from recipient ofTh1 cells. Left: Lung section stained with KJ1-26.1-biotin plus Streptavidin-FITC; Right: Lung section stained with biotinylated control antibody plus Streptavidin-FITC. (b) Lung tissue from recipient of Th2 cells. Left: Lung section stained with KJ126.1-biotin plus Streptavidin-FITC; Right: Lung section stained with biotinylated control antibody plus Streptavidin-FITC. TCR, T-cell receptor. 

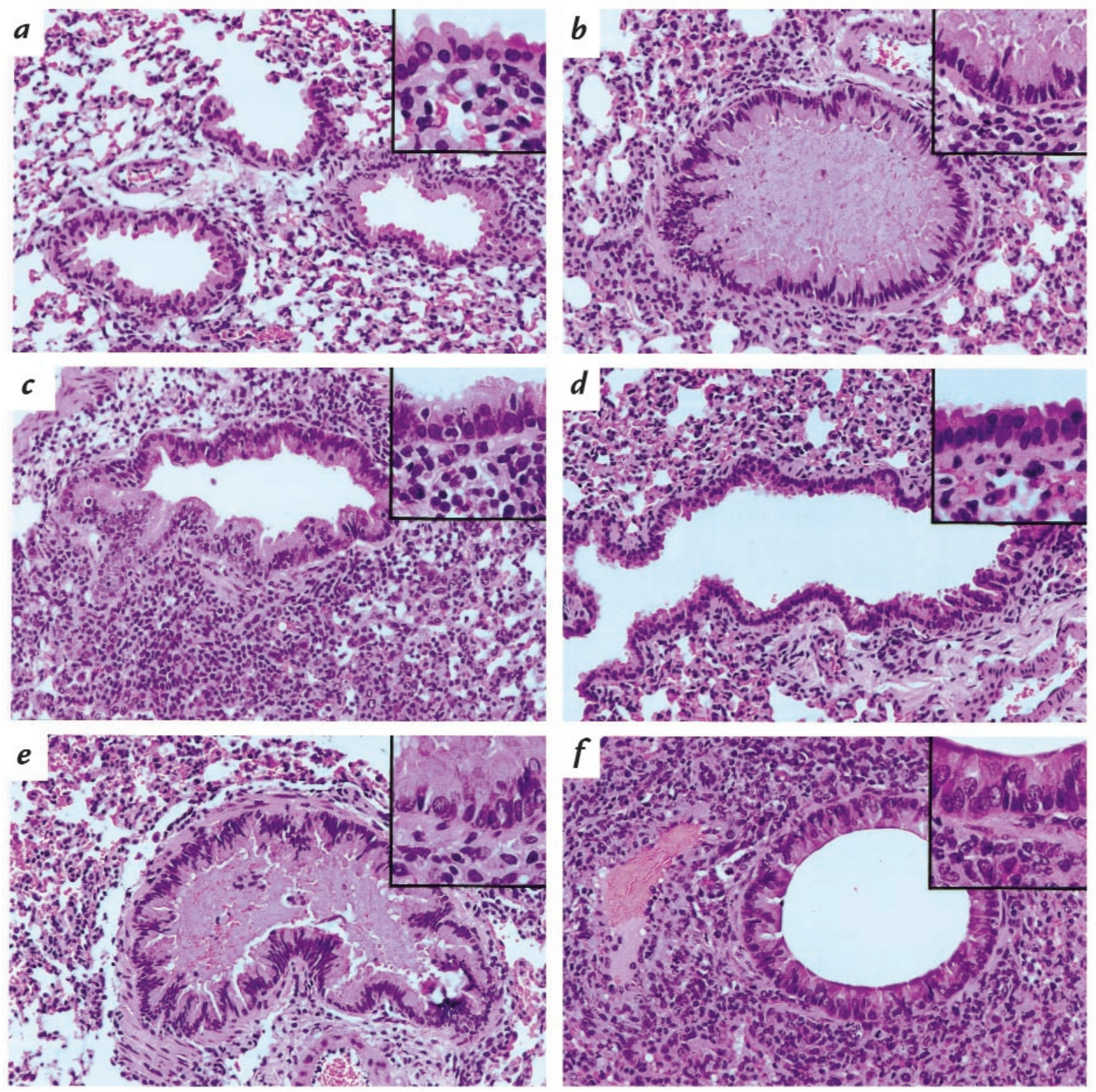

\section{Figure 3}

Histologic examination of lungs from SCID mice receiving Th1, Th2, and Th0 cells. (a) Lung tissue from control SCID mouse that received intranasal OVA but no Th cells. H\&E, $\times 250$. Inset: High-power magnification of normal bronchiolar epithelium. H\&E, $\times 400$. (b) Lung tissue from SCID mouse that received Th2 cells and intranasal OVA. Peribronchiolar mononuclear cell infiltrates are noted. The airway lumen is filled and expanded by thick mucus. H\&E, $\times 250$. Inset: High-power magnification of the airway epithelium showing tall columnar cells exhibiting abundant cytoplasmic mucin and a collarette of inflammatory cells. H\&E, $\times 400$. (c) Lung tissue from SCID mouse that received Th1 cells and intranasal OVA. Dense peribronchiolar inflammatory infiltrates are seen. The airway lumen does not contain mucus plugs. H\&E, $\times 250$. Inset: Lymphocytes are penetrating the airway epithelium and surrounding tissue spaces. H\&E, $\times 400$. (d) Lung tissue from control SCID mouse that received Th1 cells but not intranasal OVA. The bronchiole is normal with rare mononuclear cells in the peribronchiolar tissue; H\&E $\times 250$. Inset: The airway epithelium is normal. H\&E, $\times 400$. $(\boldsymbol{e})$ Lung tissue from SCID mouse that received Th0 cells and intranasal OVA. Peribronchiolar infiltrates are noted, and the lumen is filled with mucus; scattered inflammatory cells are noted. $\mathrm{H} \& \mathrm{E}, \times 250$. Inset: The airway epithelium resembles that of mice that received OVA-specific Th2 cells, with the presence of tall columnar cells with abundant cytoplasmic mucin $(b)$. ( $f$ ) Lung tissue from SCID mouse that received both Th1 and Th2 cells and intranasal OVA. Significant airway inflammation is noted, without airway mucus. $\mathrm{H \& E}, \times 250$. Inset: The epithelium displays reactive-appearing columnar cells, with inflammatory cells at the bases. $\mathrm{H} \& \mathrm{E}, \times 400$. H\&E, hematoxylin and eosin; SCID, severe combined immunodeficiency.

$\gamma$ and IL-4. The quantity of IL-4 produced by the Th0 lines was significant, although less than that of Th2 lines. The Th1, Th2, and Th0 lines were used after at least three cycles of stimulation, after the $\mathrm{T}$ cell lines achieved a stable committed phenotype (23).

In vivo transfer and detection of OVA-specific $T$ cells to the lung. To determine the effects of Th cell lines on the development of airway hyperreactivity and airway inflammation, we adoptively transferred each cell line into histocompatible SCID mice. In these experiments, we chose SCID mice to eliminate the contribution of endogenous lymphocytes, which might inhibit the func- 


\section{Figure 4}

OVA-specific Th1 cells significantly reduce the number of eosinophils induced by OVA-specific Th2 cells in BAL fluid of OVA-treated SCID mice. Four days after transfer of Th1 $\left(2.5 \times 10^{6}\right.$ cells per mouse), Th2 $(2.5 \times$ $10^{6}$ cells per mouse $)$, or Th 1 plus Th2 $\left(2.5 \times 10^{6} \mathrm{Th} 1+2.5 \times 10^{6} \mathrm{Th} 2\right.$ cells per mouse) cells in OVA-treated SCID mice, BAL was performed with three aliquots of $0.4 \mathrm{ml}$ PBS per mouse ( $n=6$ for each group). The relative number of different types of leukocytes (lung cell differentials) was determined from Hansel Stain slide preparations of BAL fluid. The data are expressed as mean \pm SEM of the percentage of each cell type derived from differentials based on 200 cells. Results are given as cells per milliliter in BAL fluid. BAL, bronchoalveolar lavage; Eos, eosinophils; Lym, lymphocytes; Mo, macrophages; Neu, neutrophils.

tion of the transferred Th cells, and which could also contribute to airway hyperreactivity, as the recipients were exposed to OVA administered intranasally. To enhance the localization of the transferred $\mathrm{T}$ cell lines into the lungs of mice, we administered OVA intranasally one day before adoptive transfer of the $T$ cell lines. One and two days later, OVA was again administered intranasally. Control mice received $\mathrm{NaCl} 0.9 \%$ instead of OVA intranasally. Four days after cell transfer, the lungs were stained with anti-TCR clonotypic antibody KJ126.1. Figure 2 shows that lungs from mice that received Th1 or Th 2 cells and intranasal OVA stained brightly with the anti-TCR antibody, indicating that the OVAspecific $\mathrm{T}$ cell lines migrated to the lungs of these mice. In contrast, lungs from mice that received Th1 or Th2 cells, but no intranasal OVA, had no staining (data not shown), indicating that migration of the OVA-specific $\mathrm{T}$ cell lines was antigen dependent.

Airway histology in recipients of $T h 1, T h 2$, and Th0 cell lines. Mice were sacrificed four days after T-cell transfer. Lungs were removed and fixed, and lung sections were stained with hematoxylin and eosin to reveal lung histology. SCID mice that received OVA but no $T$ cells had normal lung histology (Fig. 3a). Adoptive transfer of OVA-specific Th2 cells induced significant bronchiolar mucus production and induced peribronchiolar and perivascular infiltrates, consisting of lymphocytes, eosinophils, and some neutrophils (Fig. 3b). These results were similar to those reported in previous studies with Th2 cells (24). Transfer

\section{Figure 5}

Th2 and Th 0 cells, but not Th 1 cells, increase airway hyperreactivity. SCID mice received Th1, Th2, or Th0 cells $\left(2.5 \times 10^{6}\right.$ cells per mouse $)$ intravenously plus intranasal OVA. Control mice received either OVA only or cells only. Three days after adoptive cell transfer, airway hyperreactivity in response to increasing concentrations of inhaled methacholine was measured in a whole-body plethysmograph. Data are expressed as percent above baseline (mean \pm SEM); $n \geq 7$ for each data point. Cell transfer without intranasal administration of OVA had no effect on airway hyperreactivity (data not shown).

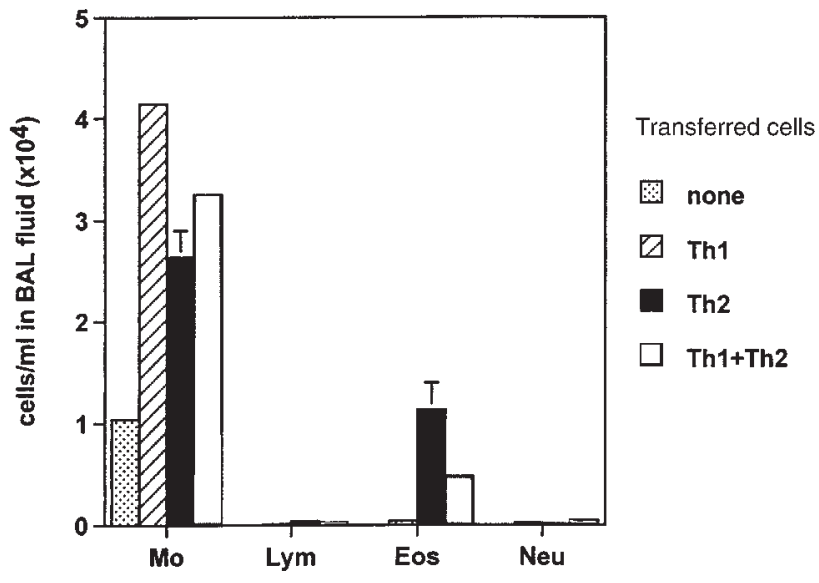

of OVA-specific Th1 cells also resulted in significant airway inflammation, with peribronchiolar and perivascular infiltrates (Fig. 3c). Th1 cells induced much less mucus production than did Th2 cells, and far more lymphocytes were present in the lungs when Th1 cells rather than Th2 cells were transferred. The inflammatory reaction with Th1 cells resembled that of moderate to severe lung allograft rejection, with dense perivascular and interstitial accumulations of small lymphocytes and immunoblasts with neutrophils and occasional eosinophils $(25,26)$. The inflammatory response with Th1 cells depended on the presence of OVA, as mice that received Th1 cells, but not OVA, had minimal lung disease (Fig. 3d). Furthermore, this inflammatory response with Th1 cells plus intranasal OVA was confined only to the lungs and was not observed in any other organ system.

Adoptive transfer of Th0 cell lines produced results similar to that observed with Th2 cell lines and induced significant airway inflammation (Fig. 3e). The production of IFN- $\gamma$ by Th0 cells did not limit the inflammatory response, as large numbers of lymphocytes, neutrophils, and some eosinophils were present in the perivascular and peribronchiolar areas of Th0 cell recipients. Transfer of both Th1 and Th2 cells together did not result in reduction of airway inflammation, although the amount of bronchiolar mucus was reduced (Fig. $3 f$ ). This indicated that OVA-specific Th1 cells were not effective in counterbalancing Th2-induced airway inflammation.

Th2 cell-induced eosinophilia is significantly reduced by Th1

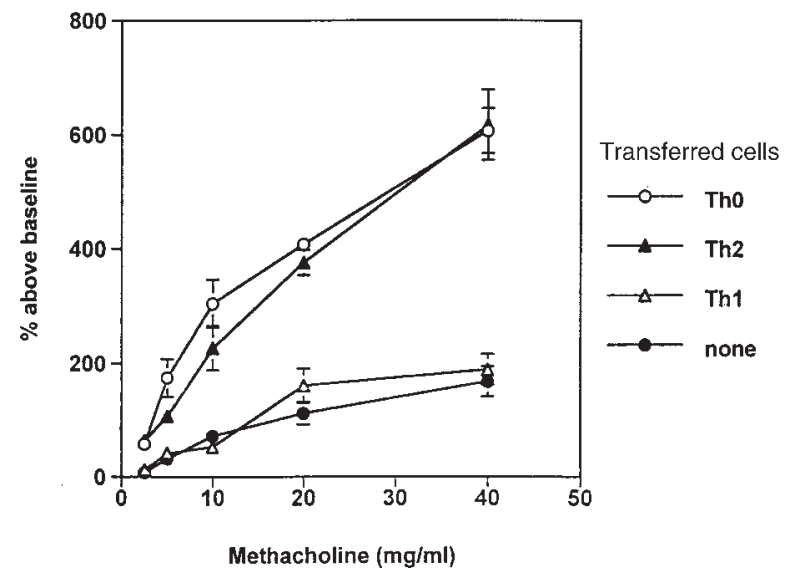




\section{Figure 6}

Th1 cells do not counterbalance airway hyperreactivity induced by Th2 cells. SCID mice received Th1 $\left(2.5 \times 10^{6}\right.$ cells per mouse) or Th2 $(2.5$ $\times 10^{6}$ cells per mouse) cells intravenously plus intranasal OVA. Other SCID mice received a mixture of Th 1 and Th2 cells in a ratio of $1: 1$ ( 2.5 $\times 10^{6}$ cells each) or 2:1 $\left(5 \times 10^{6}\right.$ Th1 cells plus $2.5 \times 10^{6}$ Th 2 cells $)(n$ $\geq 5$ for each data point). Airway hyperreactivity in response to inhaled methacholine was measured in a whole-body plethysmograph. Results are demonstrated as percent above baseline (mean \pm SEM).

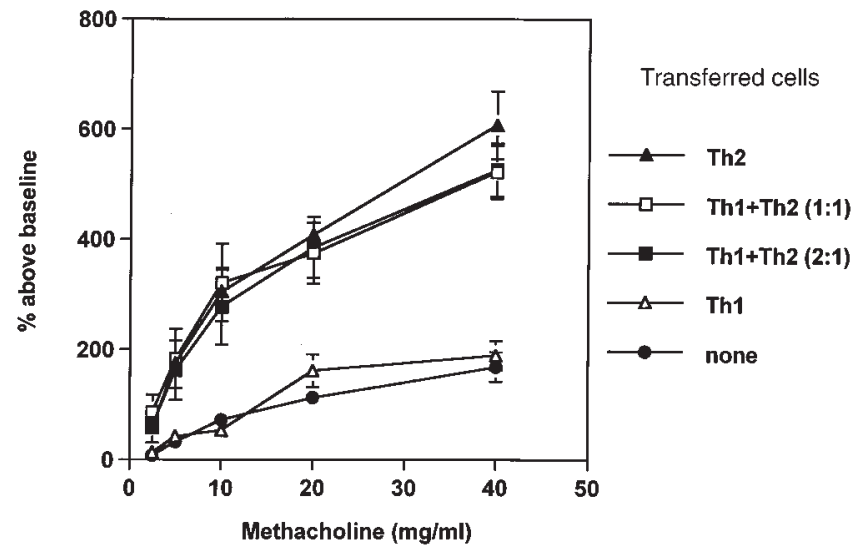

intranasal OVA, did not develop airway hyperreactivity, indicating that this response depended on the presence of Th2 cells and on the presence of airway antigen. Recipients of Th0 cell lines developed significant airway hyperreactivity that was not statistically different from that induced with Th2 cells, suggesting that the production of IFN- $\gamma$ by the T cells was not effective in reducing airway hyperreactivity. Transfer of Th1 lines, although inducing significant airway inflammation, did not induce airway hyperreactivity to methacholine. This indicated that airway hyperreactivity depends on factors produced by Th2-polarized cells and cannot be induced with inflammation-causing Th1-polarized cells.

Th1 cells do not counterbalance airway byperreactivity induced by Th2 cells. We next directly examined the capacity of Th 1 cells to counterbalance airway hyperreactivity induced by Th 2 cells by transferring a mixture of Th 1 cells and Th 2 cells into SCID mice. Figure 6 shows that although recipients of Th2 cells $\left(2.5 \times 10^{6}\right.$ cells permouse) expressed significant airway hyperreactivity, recipients of Th1 cells plus Th2 cells in a ratio of $1: 1(2.5$ $\times 10^{6}$ cells each, Th1 + Th2 [1:1]) expressed equally strong airway hyperreactivity on methacholine challenge. Even on transfer of twice as many Th1 as Th2 cells $\left(5 \times 10^{6}\right.$ Th 1 cells $+2.5 \times 10^{6}$ Th2 cells, Th1 + Th2 [2:1]), Th1 cells did not limit Th 2 cell-induced airway hyperreactivity. These results indicate that antigen-specific Th1 cells do not inhibit airway hyperreactivity induced by Th2 cells even when given in a 2:1 excess.

Th1 cells do not reduce airway byperreactivity in OVA-immu-

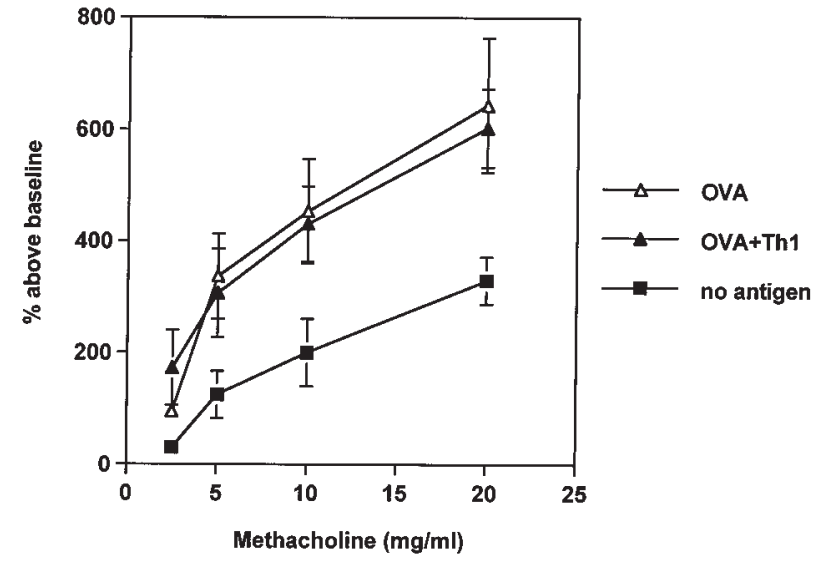

\section{Figure 7}

OVA-specific Th1 cells do not reduce airway hyperreactivity in OVAimmunized BALB/c mice. BALB/c mice were immunized with OVA (50 $\mu \mathrm{g})$ in alum intraperitoneally on days 0 and 14 , and intranasally $(50 \mu \mathrm{g}$ OVA in $50 \mu \mathrm{PBS}$ ) on days $14,25,26$, and 27 (OVA; $n=6)$. A second group of mice also received OVA-specific Th1 cells intravenously on days 14 and $25\left(2.5 \times 10^{6}\right.$ cells per mouse at each time point) (OVA + Th1; $n$ $=5)$. Control mice received alum intraperitoneally and PBS intranasally ( no antigen; $n=6$ ). Airway hyperreactivity to methacholine was determined as in Figs. 5 and 6 . Results are expressed as mean \pm SEM. Transfer of Th1 cells without administration of antigen did not have any effect on airway hyperreactivity (data not shown). 
nized $B A L B / c$ mice. To determine whether Th1 cells could inhibit the development of Th2 cells in normal mice rather than reversing the function of established Th2 effector cells, we examined the capacity of adoptively transferred Th1 cell lines to prevent the development of allergen-induced airway hyperreactivity in normal BALB/c mice. Figure 7 shows that immunization of control BALB/c mice with OVA intraperitoneally and intranasally resulted in the development of significant airway hyperreactivity. Adoptive transfer of Th1 cells during the four-week sensitization phase on days 14 and 25 did not reduce this airway hyperreactivity, although Th1 cells migrated to the lungs as proved by fluorescence staining of lung sections with anti-TCR clonotypic antibody KJ1-26.1 one day after airway measurement (data not shown). These results indicated that Th1 cells were not able to inhibit the development of a Th2 response in sensitized immunocompetent BALB/c mice.

Airway eosinophilia in OVA-immunized BALB/c mice is significantly reduced by transfer of Th1 cells. Although Th1 cells were unable to reduce airway hyperreactivity in OVAimmunized mice, Th1 cells did significantly reduce airway eosinophilia (Fig. 8), indicating that the Th1 cells functioned in vivo. Th1 cells transferred during the sensitization phase reduced the number of BAL eosinophils by more than fivefold (from $13.5 \times 10^{5}$ to $2.3 \times 10^{5}$ eosinophils $/ \mathrm{ml}$ ), although the total number of cells in BAL fluid from OVA-sensitized BALB/c mice was not significantly reduced $\left(18.1 \times 10^{5}\right.$ cells $/ \mathrm{ml}$ in BAL from control mice vs. $15.9 \times 10^{5}$ cells $/ \mathrm{ml}$ in BAL from Th1-cell recipients). Lymphocytes and neutrophils were relatively rare in BAL fluid and did not differ significantly between the groups. However, histologic analysis revealed that the inflammatory response was not reduced by transfer of Th1 cells. Hematoxylin and eosin-stained lung sections of BALB/c mice after OVA immunization and Th1 cell transfer showed dense perivascular and peribronchiolar infiltrates containing numerous lymphocytes and eosinophils (data not shown). This pattern was comparable to the histology of the OVA-immunized control group.

\section{Discussion}

The major goal of this study was to examine directly the capacity of Th1 cells to counterbalance the proasthmatic effects of Th2 cells in a murine model of asthma. The Th1/Th2 paradigm suggests that Th1 and Th2 cells counterbalance each other and that Th1 cells protect or prevent Th2-mediated allergic disease and asthma (27). However, using well-defined, phenotypically committed OVA-specific Th1 and Th2 cells expressing identical TCRs and adoptively transferred into either SCID mice or into OVA-immunized BALB/c mice, we found that OVA-specific Th1 cells failed to reverse Th2-mediated airway inflammation and airway hyperreactivity, even when given in twofold excess. These studies indicate that the Th1/Th2 paradigm, which predicts that Th1 cells downregulate allergic disease and asthma, may be more complex than initially appreciated and that suppression of allergic inflammation and Th2 activity in vivo may depend on cells other than Th1 lymphocytes.

Inasmuch as asthma is associated with the presence of

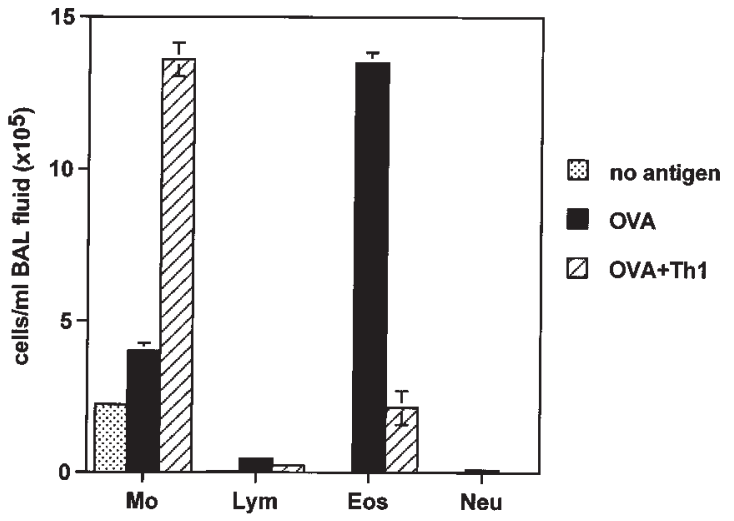

Figure 8

OVA-specific Th1 cells significantly reduce the number of eosinophils in OVA-immunized BALB/c mice. BALB/c mice were immunized with OVA $(50 \mu \mathrm{g})$ in alum intraperitoneally on days 0 and 14 and intranasally (50 $\mu \mathrm{g}$ OVA in $50 \mu \mathrm{lPBS}$ ) on days $14,25,26$, and 27 (OVA; $n=6)$. A second group of mice was immunized with OVA and additionally received OVAspecific Th1 cells intravenously on days 14 and $25\left(2.5 \times 10^{6}\right.$ cells per mouse at each time point) (OVA + Th1; $n=5)$. Control mice received alum intraperitoneally and PBS intranasally (no antigen; $n=6$ ). BAL was performed on day 29 with three aliquots of $0.4 \mathrm{ml}$ PBS per mouse, and the relative number of different types of leukocytes (lung cell differentials) was determined. The data are expressed as mean \pm SEM of the percentage of each cell type derived from differentials based on 200 cells.

lymphocytes producing Th2 cytokines (28), it is not surprising that OVA-specific Th2 cells induced severe allergic inflammatory responses and airway hyperreactivity when adoptively transferred into normal $(24,29)$ or SCID recipients (Figs. 3 and 5). We also demonstrated, however, that antigen-specific Th0 cells caused severe airway inflammation and hyperreactivity equal to those observed with Th 2 cells. This indicated that production of IFN- $\gamma$, a cytokine thought to inhibit the development of allergy and asthma $(30,31)$, by Th0 cells was insufficient to neutralize the effects of IL-4 and IL-5. Our studies differed from previous studies with Th2 cells $(24,29)$ in that we used SCID mice as recipients to eliminate the effects of host cells that could inhibit the function of the transferred Th cells or that could contribute to airway hyperreactivity on immunization with antigen. These results with SCID mice demonstrated that airway hyperreactivity can be induced by Th2 or Th0 cells in the absence of other T cells, B cells, IgE, or $\gamma \delta$ T cells. In contrast, previous studies with B cell-deficient mice (32) and $\gamma \delta \mathrm{T}$ cell-deficient mice (33) suggested that B cells, IgE, and $\gamma \delta$ T cells were required for the induction of airway hyperreactivity or allergic airway inflammation. It is possible, however, that $\mathrm{B}$ cells or $\gamma \delta \mathrm{T}$ cells are required for the development of Th2 effector cells from naive precursor cells but that once Th2 cells have become activated, such "accessory cells" are not essential for expression of airway inflammation and hyperreactivity.

Our results demonstrating the inability of Th1 cells to neutralize the effects of Th2 cells are surprising in view of numerous studies that suggested that allergen-specific Th1 cells might suppress allergic inflammation. For example, we and others have shown that conventional allergen immunotherapy, which improves symptoms in 
allergic and asthmatic patients, reduces IL-4 production (9) and increases IFN- $\gamma$ production in an allergen-specific fashion $(10,11)$. Immunization with IL-12-modified allergen (34), with heat-killed Listeria monocytogenes as adjuvant (35), with intratracheal IL-12, or with naked DNA plasmids containing cDNA for allergens $(36,37)$ also resulted in a switch in cytokine production in allergen-specific $\mathrm{CD}^{+} \mathrm{T}$ cells and caused a reduction in allergen-induced airway hyperreactivity (38). These observations suggest that allergen-specific Th1-polarized responses suppress allergic inflammation, although no previous studies have examined the capacity of Th1 cells to inhibit Th2-induced airway hyperreactivity directly.

On the other hand, there is increasing evidence that Th1 and Th 2 cells may not always antagonize each other. First, IFN- $\gamma$ has been identified in BAL fluid and serum of asthmatic patients, suggesting that Th1-like cells may in fact contribute to, rather than inhibit, the pathology in asthma $(39,40)$. In addition, Th1 cells are not found in large numbers in the lungs or mucus membranes of nonallergic or nonasthmatic individuals after allergen exposure, as would be predicted if Th1 cells reduced airway inflammation. Moreover, in a murine model of autoimmunity, myelin basic protein-specific Th2 cells, when transferred into immunodeficient mice, exacerbated rather than prevented experimental autoimmune encephalomyelitis (14). Similarly, attempts to use autoantigen-specific Th2 cells to confer protection against Th1-induced diabetes mellitus unexpectedly produced intense and generalized pancreatitis and subsequent diabetes mellitus (15). These studies together indicate that Th1 and Th2 cells may not always balance each other's function in a dichotomous paradigm, but rather may in some instances be unexpectedly harmful, not only in autoimmune disease but also in allergic disease and asthma.

We found that antigen-specific Th1 cells when adoptively transferred to SCID mice induced considerable airway inflammation, resembling severe delayed-type hypersensitivity reactions, lung allograft rejection (25), or hypersensitivity pneumonitis (41). The inflammatory response caused by Th1 cells depended on the presence of antigen and occurred only in the lungs of the recipient mice. Surprisingly, even though Th1 cells induced severe airway inflammation, they did not cause airway hyperreactivity. These studies indicate that inflammation in and of itself is not important for the development of airway hyperreactivity, although $\mathrm{CD}^{+} \mathrm{T}$ cells appear to be essential for the development of airway hyperreactivity (42). The precise factors produced by $\mathrm{CD}^{+} \mathrm{T}$ cells that are important for the development of airway hyperreactivity, however, have not yet been identified, but they appear not to be IL-4 and IL5 (42) nor those produced by Th1 cells (Fig. 5). Further studies are necessary to determine whether other factors produced by Th2 cells, such as IL-9 (43) or IL-13 (44), are essential for the induction of airway hyperreactivity.

Although we found that Th1 cells could not reverse Th2-induced airway hyperreactivity in SCID or in OVAimmunized BALB/c mice, Th1 cells were able to reduce the number of airway eosinophils and reduce intrabronchiolar mucus production induced by Th2 cells. Similarly, we reported previously (45) that adoptively transferred Th1 clones could inhibit the capacity of Th2 clones to induce antigen-specific IgE synthesis. This indicated not only that the adoptively transferred Th1 cells functioned in vivo after transfer and could modify some, although not all, functions of Th2 effector cells, but also that the presence of eosinophils may not be essential for the development of airway hyperreactivity, as has been suggested previously (46). The resistance of Th 2 cell function to modification by Th 1 cells may be due in part to the fact that Th2 effector cells are terminally differentiated with fixed cytokine profiles (23) and cease to express IL-12 and IL-18 receptors $(47,48)$.

It is possible that Th1 cells may in fact be beneficial in asthma if they are present early on in high numbers before activated effector Th2 cells are present. In such instances, while being ineffective in reversing the function of effector Th2 cells, Th1 cells may be capable of blocking the development of Th2 cells from naive $\mathrm{T}$ cells and of preventing the induction of airway hyperreactivity. Alternatively, other cell types - e.g., transforming growth factor- $\beta$-producing $\mathrm{CD}^{+}$antigen-specific Th3 cells (49), Tr1 cells (50), $\gamma \delta$ cells (51), or CD8 ${ }^{+}$cells $(52,53)$ - may be more important than Th1 cells in downregulating allergic inflammation and hyperreactivity. Further studies are required to determine how Th1 cells or other cell types regulate allergic inflammation and airway hyperreactivity. Such studies are particularly important as prerequisites for the development of therapies focused on immunomodulation of deleterious Th2-polarized responses.

In summary, using well-defined polarized Th cells, we showed that antigen-specific Th 1 cells were ineffective in reducing airway hyperreactivity induced by Th 2 cells and caused serious airway inflammation but not airway hyperreactivity. In contrast, Th2 and Th0 cells induced considerable airway hyperreactivity, in the absence of B cells, IgE, or other lymphocytes. Our results raise concerns regarding the protective effects of Th1 cells in allergy and asthma and regarding the feasibility of Th1-based therapies for these clinical problems.

\section{Acknowledgments}

We thank G. Trinchieri for the anti-IL-12 MAB;J. Ohara and B. Paul for MAB 11B11; M. Howard for MABs BVD4, BVD6, SXC.1, and 2A5; J. Kappler and P. Marrack for anti-clonotype antibody KJ1-26.1; T. Mosmann for MABs S4B6 and XMG1.2; S. Levy (Stanford University) for MAB 4G10; and D.B. Lewis (Stanford University) for assistance in measuring airway hyperreactivity in mice. This work was supported by grants RO1AI24571 and RO1AI26322 from the US Public Health Service/National Institutes of Health. G. Hansen is a Fellow of the Deutsche Forschungsgemeinschaft (Ha2799/1-1).

\footnotetext{
1. Gergen, P.J., and Weiss, K.B. 1990. Changing patterns of asthma hospitalization among children: 1979 to 1987. JAMA. 264:1688-1692.

2. Kirby, J.G., Hargreave, F.E., Gleich, G.J., and O'Byrne, P.M. 1987. Bronchoalveolar cell profiles of asthmatic and non-asthmatic subjects. Am. Rev. Respir. Dis. 136:379-383.

3. Bradley, L.B., et al. 1991. Eosinophils, T-lymphocytes, mast cells, neutrophils and macrophages in bronchial biopsy specimens from atopic subjects with asthma: comparison with biopsy specimens from atopic subjects without asthma and normal control subjects and relationship to bronchial hyperresponsiveness. J. Allergy Clin. Immunol. 88:661-674.

4. Umetsu, D.T., and DeKruyff, R.H. 1997. Th1 and Th2 CD4+ cells in human allergic diseases. J. Allergy Clin. Immunol. 100:1-6.

5. Martinez, F.D., et al. 1995. Asthma and wheezing in the first six years of life. N. Engl. J. Med. 332:133-138.
} 
6. Abbas, A.K., Murphy, K.M., and Sher, A. 1996. Functional diversity of helper T lymphocytes. Nature. 383:787-793

7. Coffman, R.L., et al. 1988. The role of helper T cell products in mouse B cell differentiation and isotype regulation. Immunol. Rev. 102:5-28.

8. Wierenga, E.A., et al. 1991. Human atopen-specific types 1 and $2 \mathrm{~T}$ helper cell clones. J. Immunol. 147:2942-2949.

9. Secrist, H., Chelen, C.J., Wen, Y., Marshall, J.D., and Umetsu, D.T. 1993. Allergen immunotherapy decreases interleukin 4 production in CD4+ T cells from allergic individuals. J. Exp. Med. 178:2123-2130.

10. Jutel, M., et al. 1995. Bee venom immunotherapy results in decrease of IL-4 and IL-5 and increase of IFN-gamma secretion in specific allergenstimulated T cell cultures. J. Immunol. 154:4187-4194.

11. Varney, V.A., et al. 1993. Influence of grass pollen immunotherapy on cellular infiltration and cytokine mRNA expression during allergeninduced late-phase cutaneous responses. J. Clin. Invest. 92:644-651.

12. Oro, A.S., Guarino, T.J., Driver, R., Steinman, L., and Umetsu, D.T. 1996. Regulation of disease susceptibility: decreased prevalence of IgE-mediated allergic disease in patients with multiple sclerosis. J. Allergy Clin. Immunol. 97:1402-1408.

13. Shirakawa, T., Enomoto, T., Shimazu, S., and Hopkin, J.M. 1997. The inverse association between tuberculin responses and atopic disorder. Science. 275:77-79.

14. Lafaille, J.J., et al. 1997. Myelin basic protein-specific T helper 2 (Th2) cells cause experimental autoimmune encephalomyelitis in immunodeficient hosts rather than protect them from the disease. J. Exp. Med. 186:307-312

15. Pakala, S.V., Kurrer, M.O., and Katz, J.D. 1997. T helper 2 cells induce acute pancreatitis and diabetes in immune-compromised nonobese diabetic mice. J. Exp. Med. 186:299-306.

16. Genain, C.P., et al. 1996. Late complications of immune deviation therapy in a nonhuman primate. Science. 274:2054-2056.

17. Bosma, G.C., Custer, R.P., and Bosma, M.J. 1983. A severe combined immunodeficiency mutation in the mouse. Nature. 301:527-530.

18. Murphy, K.M., Heimberger, A.B., and Loh, D.Y. 1990. Induction by antigen of intrathymic apoptosis of CD4+CD8+TCRlo thymocytes in vivo. Science. 250:1720-1723.

19. Marrack, P., Shimonkevitz, R., Hannum, C., Haskins, K., and Kappler, J. 1983. The major histocompatibility complex-restricted antigen receptor on T cells. IV. An antiidiotypic antibody predicts both antigen and Ispecificity. J. Exp. Med. 158:1635-1646.

20. Tsuyuki, S., Stuyuki, J., Einsle, K., Kopf, M., and Coyle, A.J. 1997. Costimulation through B7-2 (CD86) is required for the induction of a lung mucosal Th2 immune response and altered airway responsiveness. J. Exp. Med. 185:1671-1679.

21. Hamelmann, E., et al. 1997. Noninvasive measurement of airway responsiveness in allergic mice using barometric plethysmography. Am. J. Respir. Crit. Care Med. 156:766-775.

22. Macaulay, A.E., DeKruyff, R.H., and Umetsu, D.T. 1998. Antigen-primed T cells from B cell-deficient JHD mice fail to provide B cell help. $J$. Immunol. 160:1694-1700.

23. Murphy, E., et al. 1996. Reversibility of T helper 1 and 2 populations is lost after long-term stimulation. J. Exp. Med. 183:901-913.

24. Cohn, L., Homer, R.J., Marinov, A., Rankin, J., and Bottomly, K. 1997. Induction of airway mucus production By T helper 2 (Th2) cells: a critical role for interleukin 4 in cell recruitment but not mucus production. J. Exp. Med. 186:1737-1747.

25. Berry, G.J., and Billingham, M.E. 1995. The pathology of combined heart-lung and lung transplantation. In Thoracic transplantation. S.J. Shumway, and N.E. Shumway, editors. Blackwell Science Inc. Cambridge, United Kingdom. 331-347.

26. Ohori, N.P., and Yousem, S.A. 1996. Pathology of lung transplantation. In Solid organ transplant rejection: mechanism, pathology and diagnosis. $\mathrm{K}$ Solez, L.C. Racusen, and M.E. Billingham, editors. Marcel Dekker Inc. New York, NY. 161-185

27. Romagnani, S. 1994. Lymphokine production by human T cells in disease states. Ann. Rev. Immunol. 12:227-257.

28. Robinson, D.S., et al. 1992. Predominant Th2-like bronchoalveolar Tlymphocyte population in atopic asthma. N. Engl. J. Med. 326:298-304.

29. Li, X.M., Schofield, B.H., Wang, Q.F., Kim, K.H., and Huang, S.K. 1998. Induction of pulmonary allergic responses by antigen-specific Th2 cells. J. Immunol. 160:1378-1384.

30. Tang, M.L., Kemp, A.S., Thorburn, J., and Hill, D.J. 1994. Reduced interferon-gamma secretion in neonates and subsequent atopy. Lancet
344:983-985

31. Boguniewicz, M., et al. 1995. The effects of nebulized recombinant interferon-gamma in asthmatic airways. J. Allergy Clin. Immunol. 95:133-135.

32. Hamelmann, E., et al. 1997. Allergic airway sensitization induces T cell activation but not airway hyperresponsiveness in B cell-deficient mice. Proc. Natl. Acad. Sci. USA. 94:1350-1355.

33. Zuany-Amorim, C., et al. 1998. Requirement for gd T cells in allergic airway inflammation. Science. 280:1265-1267.

34. Kim, T.S., et al. 1997. An OVA-IL-12 fusion protein is more effective than OVA plus rIL-12 in inducing a Th1-dominated immune response and inhibiting antigen-specific IgE production. J. Immunol. 158:4137-4144.

35. Yeung, V.P., Gieni, R.S., Umetsu, D.T., and DeKruyff, R.H. 1998. Heat killed Listeria monocytogenes as an adjuvant converts established Th2dominated immune responses into Th1-dominated responses. J. Immunol. 161:4146-4152.

36. Hsu, C.H., et al. 1996. Immunoprophylaxis of allergen-induced immunoglobulin E synthesis and airway hyperresponsiveness in vivo by genetic immunization. Nat. Med. 2:540-544.

37. Raz, E., et al. 1996. Preferential induction of a Th1 immune response and inhibition of specific IgE antibody formation by plasmid DNA immunization. Proc. Natl. Acad. Sci. USA. 93:5141-5145.

38. Gavett, S.H., et al. 1995. Interleukin 12 inhibits antigen-induced airway hyperresponsiveness, inflammation, and Th2 cytokine expression in mice. J. Exp. Med. 182:1527-1536.

39. Cembrzynska-Nowak, M., Szklarz, E., Inglot, A.D., and TeodorczykInjeyan, J.A. 1993. Elevated release of tumor necrosis factor-alpha and interferon-gamma by bronchoalveolar leukocytes from patients with bronchial asthma. Am. Rev. Respir. Dis. 147:291-295.

40. Hessel, E.M., et al. 1997. Development of airway hyperresponsiveness is dependent on interferon-gamma and independent of eosinophil infiltration. Am. J. Respir. Cell Mol. Biol. 16:325-334.

41. Schuyler, M., Gott, K., Cherne, A., and Edwards, B. 1997. Th1 CD4+ cells adoptively transfer experimental hypersensitivity pneumonitis. Cell. Immunol. 169:169-175.

42. Hogan, S.P., et al. 1998. A novel T cell-regulated mechanism modulating allergen-induced airways hyperreactivity in $\mathrm{BALB} / \mathrm{c}$ mice independently of IL-4 and IL-5. J. Immunol. 161:1501-1509.

43. Temann, U.-A., Geba, G.P., Rankin, J.A., and Flavell, R.A. 1998. Expression of Interleukin 9 in the lungs of transgenic mice causes airway inflammation, mast cell hyperplasia, and bronchial hyperresponsiveness. J. Exp. Med. 188:1307-1320.

44. Urban, J.F., Jr., et al. 1998. IL-13, IL-4Ralpha, and Stat6 are required for the expulsion of the gastrointestinal nematode parasite Nippostrongylus brasiliensis. Immunity. 8:255-264.

45. Rizzo, L.V., DeKruyff, R.H., Umetsu, D.T., and Capsi, R.R. 1995. Regulation of the interaction between Th1 and Th2 T cell clones to provide help for antibody production in vivo. Eur. J. Immunol. 25:708-716.

46. Corry, D.B., et al. 1996. Interleukin 4, but not interleukin 5 or eosinophils, is required in a murine model of acute airway hyperreactivty. J. Exp. Med. 183:109-117.

47. Szabo, S.J., Dighe, A.S., Gubler, U., and Murphy, K.M. 1997. Regulation of the interleukin (IL)-12R beta 2 subunit expression in developing $\mathrm{T}$ helper 1 (Th1) and Th2 cells. J. Exp. Med. 185:817-824.

48. Xu, D., et al. 1998. Selective expression and functions of interleukin 18 receptor on $\mathrm{T}$ helper (Th) type 1 but not Th2 cells. J. Exp. Med. 188:1485-1492.

49. Chen, Y., Kuchroo, V.K., Inobe, J., Hafler, D.A., and Weiner, H.L. 1994. Regulatory $\mathrm{T}$ cell clones induced by oral tolerance: suppression of autoimmune encephalomyelitis. Science. 265:1237-1240.

50. Groux, H., et al. 1997. A CD4+ T-cell subset inhibits antigen-specific Tcell-responses and prevents colitis. Nature. 389:737-742.

51. Ferrick, D.A., et al. 1995. Differential production of interferon-gamma and interleukin- 4 in response to Th1- and Th2-stimulating pathogens by gamma delta T cells in vivo. Nature. 373:255-257.

52. McMenamin, C., and Holt, P.G. 1993. The natural immune response to inhaled soluble protein antigens involves major histocompatibility complex (MHC) class I-restricted CD8+ T cell-mediated but MHC class IIrestricted CD4+ T cell-dependent immune deviation resulting in selective suppression of immunoglobulin E production. J. Exp. Med. 178:889-899.

53. Rocklin, R.E., Sheffer, A., Greineder, D.K., and Melmon, K.L. 1980. Generation of antigen-specific suppressor cells during allergy desensitization. N. Engl. J. Med. 302:1213-1219. 